\title{
Erratum to: Quantifiers and Cognition: Logical and Computational Perspectives
}

\author{
Jakub Szymanik
}

\section{Erratum to:}

J. Szymanik, Quantifiers and Cognition: Logical and Computational Perspectives, Studies in Linguistics and Philosophy 96, DOI 10.1007/978-3-319-28749-2

The book was inadvertently published without the updated text in Acknowledgment in the book frontmatter. The book frontmatter has been updated with the change.

The updated original online version of the book can be found at 10.1007/978-3-319-28749-2

J. Szymanik $(\square)$

Institute for Logic, Language and Computation, University of Amsterdam,

Amsterdam, The Netherlands

e-mail: jakub.szymanik@gmail.com

(C) Springer International Publishing Switzerland 2017

E1

J. Szymanik, Quantifiers and Cognition: Logical and Computational Perspectives, Studies in Linguistics, and Philosophy 96, DOI 10.1007/978-3-319-28749-2_12 